\title{
Educação de jovens e adultos e os conhecimentos tecnocientíficos: analisando as relações entre ciência, tecnologia e matemática
}

\author{
Daiane Martins Bocasanta* \\ Fernanda Wandere** \\ Gelsa Knijnik $^{* * *}$
}

\begin{abstract}
Resumo
$\mathrm{O}$ artigo apresenta resultados de uma pesquisa que investigou como alunos da Educação de Jovens e Adultos se posicionam em relação aos conhecimentos tecnocientíficos. Para isso, foi realizado um trabalho pedagógico no qual os estudantes discutiram sobre ciência, tecnologia e matemática. Essas enunciações consistiram no material empírico que foi examinado com teorizações de Michel Foucault. A análise mostrou que ciência e tecnologia estão relacionadas à noção de progresso e desenvolvimento. A matemática é vista como uma área que impulsiona os avanços científicos e tecnológicos, sendo vinculada à inteligência e à capacidade de "acessar o potencial do ser humano".

Palavras-chave: Educação de Jovens e Adultos; Ciência; Tecnologia; Matemática; Michel Foucault.
\end{abstract}

\section{Education of youths and adults and the techno-scientific knowledge: analyzing the relationship between science, technology and mathematics}

\begin{abstract}
The paper presents results of a research that investigated how students of the Education of youths and adults positioned themselves in relation to techno-scientific knowledge. For this, it performed a pedagogical work in which students discussed science, technology and mathematics. The enunciations consisted of empirical material that was examined with theories of Michel Foucault. The analysis showed that science and technology are related to the notion of progress and development. Mathematics is seen as an area that boosts the scientific and technological advances, being linked to intelligence and ability "to access the potential of the human being."

Keywords: Education of youths and adults; science; technology; mathematics; Michel Foucault.
\end{abstract}

\section{Introdução}

O presente artigo é fruto de uma pesquisa que consistiu em analisar como alunos de alfabetização e pós-alfabetização da Educação de Jovens e Adultos (EJA) do Colégio de Aplicação da Universidade Federal do Rio Grande do Sul (UFRGS) se posicionam em relação ao que comumente consideramos como conhecimentos tecnocientíficos. Para isso, foi realizado um trabalho pedagógico no qual os estudantes foram convidados a discutir sobre ciência - tecnologia e o lugar que a matemática ocupa nessa articulação. As enunciações produzidas pelos alunos foram tomadas como material empírico, sendo examinadas com teorizações alinhadas ao pensamento de Michel Foucault.

Esta pesquisa insere-se nas discussões que marcam o campo da Educação de Jovens e Adultos, modalidade de ensino que, ao longo dos anos, vem recebendo mais atenção por parte do poder público e de pesquisadores de diversas áreas, em especial, da Educação. Em efeito, a EJA ganha destaque uma vez que ainda são elevados os índices de analfabetismo no Brasil e o número de jovens e adultos que não concluíram as etapas do Ensino Fundamental e Médio. Em um estudo recente sobre as políticas de educação de jovens e adultos em âmbito nacional e internacional, Di Pierro e Haddad (2015) destacam que as taxas de alfabetização da população brasileira com 15 anos ou mais avançaram apenas 3\% no período de 2004 a 2013. Os indicadores de escolaridade da população adulta mostraram pequeno aumento nesse mesmo período: subiu de 6,4 para 7,7 o número médio de anos de estudo da população brasileira acima de 25 anos. Além disso, os autores destacam uma redução de $24,3 \%$ nas matrículas na EJA no Ensino Fundamental e Médio entre 2007 a 2013.

Os dados apresentados indicam que é grande o número de jovens e adultos que não frequentaram a escola ou que dela se evadiram, fazendo com que, ao longo dos anos, políticas públicas e programas educacionais endereçados a

\footnotetext{
*Endereço eletrônico: daianebocasanta@gmail.com

***Endereço eletrônico: fernandawanderer@gmail.com

****Endereço eletrônico: gelsak@unisinos.br
} 
este grupo tenham sido criados e/ou ampliados. No Brasil, o reconhecimento do direito dos jovens e adultos à escolarização é fruto do processo de democratização que emerge entre os anos de 1980 e 1990, culminando na elaboração de uma Constituição, em 1988, e, anos depois, em 1996, na Lei de Diretrizes e Bases da Educação Nacional, que garantem o direito à educação para crianças, jovens e adultos (ibid.).

A conquista desse direito tem produzido efeitos tanto na criação de programas e propostas curriculares para jovens e adultos, como também na ampliação das pesquisas acadêmicas. Esses trabalhos, como mostram Soares, Silva e Soares (2015), servem-se basicamente das teorizações de Paulo Freire, uma das grandes referências na área. Assim, são evidentes nas produções sobre a EJA enunciações que se referem à necessidade de uma prática pedagógica dialógica, capaz de constituir sujeitos autônomos e críticos, que atuem na construção de uma nova sociedade (mais humana, solidária e justa).

Realizando uma análise sobre a produção acadêmica na área da EJA, no Brasil, nos últimos anos, Oliveira, Dias e Mota Neto (2012) identificaram que as pesquisas articulam-se com campos como políticas educacionais, currículo, processos de ensino e aprendizagem, formação de professores, educação e cultura e tecnologias educacionais. Entre os autores nacionais mais utilizados como referência estão Sergio Haddad, Maria Clara Di Pierro, Leôncio Soares e Vera Masagão Ribeiro. Em relação às áreas de conhecimento, os trabalhos estão concentrados na Educação, mas perpassam também pelo Ensino de Ciências, Ensino de Matemática, Artes Cênicas, Enfermagem, Psiquiatria, Letras e Linguística.

Essas pesquisas têm possibilitado, não só um acúmulo de conhecimentos relevantes para a EJA, mas também análises e reflexões sobre as políticas públicas, as especificidades e os desafios presentes na EJA e as práticas desenvolvidas em escolas. Haddad e Di Pierro (2015) destacam quatro dimensões presentes nas políticas endereçadas aos jovens e adultos. Uma delas refere-se à ampliação de seus direitos, que passam a receber a oferta de cursos e programas não só para a alfabetização e conclusão do Ensino Fundamental, mas Ensino Médio e também profissional. A segunda dimensão relaciona-se ao fato de que com a institucionalização da EJA nas políticas públicas de educação básica foram realizadas experiências de ensino que potencializaram novas ações educativas e reorientaram algumas das políticas já existentes. A terceira dimensão é que muitas das ações e programas da área da EJA são interrompidos ou cancelados, com falta de compromissos efetivos por parte do poder público. E, a quarta dimensão, diz respeito à concepção de educação que sustenta algumas das propostas pedagógicas da EJA, que se mantem alinhada à preparação para o mercado de trabalho seguindo os princípios neoliberais, em detrimento de uma formação que contemple discussões éticas, sociais e políticas.

Em relação às especificidades e aos desafios presentes na EJA, pode-se mencionar o trabalho de Silva e Moura (2013). As autoras destacam que os desafios relacionam-se com a evasão, mobilizada por fatores como a grande distância da escola até a casa, o desemprego, a desmotivação em relação aos estudos, a impossibilidade de frequentar a escola nos horários estabelecidos e dificuldades de aprendizagem. Outro problema, aliado a esse, refere-se à permanência dos estudantes nas escolas, que exige dos professores uma formação voltada às especificidades desse grupo e uma reflexão sobre planejamento, avaliação e conhecimentos a serem trabalhados. Essa questão está relacionada também com as fragilidades na formação inicial dos professores que pouco aborda a EJA, a escassa produção de materiais didáticos para essa área e a falta de uma formação continuada mais eficaz. Sobre os processos pedagógicos que constituem a EJA, apontamos trabalhos como os de Di Pierro (2005) e Fonseca $(2002,1999)$. As autoras destacam que tais processos estão marcados pela concepção compensatória, ou seja, a escolarização tem como função a reposição de estudos não realizados na infância ou adolescência.

Em relação às diferentes áreas do conhecimento, no caso desse estudo, Educação em Ciências e Educação Matemática, destacamos algumas pesquisas. Araujo Junior (2011) desenvolveu um trabalho com alunos da EJA de uma escola pública do Distrito Federal discutindo saberes escolares e saberes da experiência numa oficina sobre conhecimentos de zoologia. Araujo (2011), na mesma direção, analisou uma prática pedagógica interdisciplinar que envolveu a educação ambiental e a EJA, focando questões de sustentabilidade no contexto da pesca artesanal. Lima (2011) examinou, com os alunos da EJA, campanhas ambientais (sobre queimadas, enchentes, desmatamento e água) veiculadas em Mato Grosso, visando educar e promover mudanças de hábitos nos estudantes. Os dados mostram a dificuldade dos 
alunos da EJA em relacionar os conceitos da Física com o conteúdo abordado nas campanhas.

Ainda na área da Educação em Ciências, mas aproximando-se de discussões sobre formação científica, foco deste artigo, mencionamos o estudo de Costa e Strieder (2008) sobre o ensino de ciências e a formação da cultura científica na EJA. A investigação realizada buscou compreender como a ciência e a tecnologia podem fazer parte do cotidiano da população e aproximar os alunos do exercício de sua cidadania. Destacamos também o trabalho de Maceno (2013) que problematizou as concepções sobre ciências manifestadas por seis alunos de uma turma de Educação de Jovens e Adultos. A análise mostrou que os estudantes tomam a ciência como puramente técnica, generalista e salvacionista, isenta de limitações e implicações sociais.

Nas áreas da EJA e Educação Matemática são referências os estudos de Knijnik (2006) e Fonseca $(2002,1999)$. Os trabalhos mostram que jovens e adultos produzem saberes matemáticos ao longo de suas trajetórias de vida que diferem, muitas vezes, do conhecimento escolar. Os programas da EJA, de um modo geral, não consideram os jogos de linguagem matemáticos gerados nessas diferentes formas de vida. Assim, o ensino pode contribuir para acelerar o processo de exclusão, pois, ao mesmo tempo que os saberes matemáticos dos alunos não são legitimados, eles precisam aprender - e, na maior parte das vezes não conseguem -, os jogos de linguagem matemáticos da forma de vida escolar. Sobre as propostas pedagógicas postas em ação em muitas escolas, destacamos o estudo de Thees e Fantinato (2013) que analisaram práticas de professores de matemática que atuam na EJA. A pesquisa indicou que as tais práticas estão marcadas por um estilo de ensino direto e expositivo, baseado na resolução de exercícios, não fazendo uso de materiais didáticos ou atividades além do livro didático.

Essas pesquisas mostram que, em termos de referenciais teóricos, praticamente todas sustentamse nos estudos de Paulo Freire. Além disso, a revisão que empreendemos enfatiza que são poucas as relações estabelecidas entre as áreas da Educação em Ciências e Educação Matemática. Outra questão a ser destacada é que muitos estudos sustentam-se na realização de práticas pedagógicas com os alunos a fim de questionar e discutir temas para, após isso, desenvolver atividades que possam superar/avançar/produzir outras formas de ver e conceber esses temas e a própria educação.
Nosso artigo, mesmo apresentando alguns pontos de convergência com os estudos apresentados, difere deles no que se refere à base teórica, aqui sustentada nas teorizações de Michel Foucault. Além disso, ao discutir com os alunos concepções sobre a articulação "ciência e tecnologia" e o lugar da matemática nessa articulação não tivemos o propósito de desenvolver atividades que fizessem os estudantes modificar suas concepções ou que chegassem "a um outro lugar". Nosso intuito foi, simplesmente, problematizar e questionar algumas dessas concepções, pensando sobre seus efeitos para a área da Educação.

\section{O lócus da pesquisa}

Esse estudo foi realizado no Colégio de Aplicação da UFRGS, instituição conhecida entre sua comunidade escolar como CAp. Tal espaço escolar surgiu através de um decreto federal de 1946, porém iniciou suas atividades apenas a partir de 1954, ligada a um departamento da Faculdade de Filosofia da UFRGS, com o intuito de constituir campo de investigação pedagógica para licenciandos.

O colégio funcionou até a década de 90 do século passado no Campus Central da universidade, sendo então, transferido para sede própria no terreno do Campus do Vale. Essa mudança, bem como a modificação do processo de ingresso, que deixou de ser por meio de seleção por provas para sorteio universal anos antes, fez com que houvesse mudanças quanto ao público atendido na escola. Desse modo, a escola que antes tinha entre a maior parte de seu corpo discente jovens provenientes de famílias abastadas e/ou com algum destaque social da capital do Rio Grande do Sul, passou a receber alunos de diferentes níveis sócio-econômicos, tanto de Porto Alegre quanto de Viamão, cidade bastante próxima de seu novo endereço.

A maior parte do corpo docente do CAp é atualmente composta por professores mestres e doutores em suas áreas de formação e, assim como ocorre com na universidade, há o envolvimento desses profissionais, tanto em atividades de ensino, quanto em atividades de pesquisa e extensão. As turmas são organizadas por projetos. Destarte, o Projeto Unialfas é conformado pelos Anos Iniciais do Ensino Fundamental, o Projeto Amora compreende sextos e sétimos anos dos Anos Finais do Ensino Fundamental, o Projeto Pixel é formado por oitavos e nonos anos dos Anos Finais do Ensino 
Fundamental, o Projeto Ensino Médio comporta os três anos do Ensino Médio e o Projeto EJA configura-se pelo atendimento de uma turma de Alfabetização e Pós-Alfabetização, turmas de Ensino Médio dessa modalidade e, em breve, uma turma correspondente aos Anos Finais do Ensino Fundamental. Cada projeto é atendido por uma equipe de trabalho formada por professores e orientação educacional.

Os alunos que participaram deste estudo compõem um grupo de estudantes de uma turma de alfabetização e pós-alfabetização da Educação de Jovens e Adultos, na qual uma das autoras atuava como docente. A turma em questão era formada (em 2016/1) por 6 homens, com idades entre 33 e 68 anos, sendo que todos os participantes têm sua trajetória profissional ligada à Universidade. As profissões declaradas pelos alunos eram porteiro, zelador, jardineiro e servente de obras. Um dos alunos já estava aposentado e outro, apesar de atuar junto a um dos campi universitários da UFRGS, é, na verdade, profissional ligado a uma empresa terceirizada atuante na instituição.

O nível de escolarização dos sujeitos denotava a heterogeneidade do grupo, especialmente no que concerne a leitura e escrita. Desse modo, três estudantes poderiam ser considerados alfabetizados e três ainda em processo de alfabetização. Esse grupo foi composto no ano de 2015, numa parceria do Colégio de Aplicação com a Universidade ao qual está ligado, visando atender a demanda de funcionários com baixa escolaridade que ainda fazem parte de seu quadro. Devido a essa parceria, os alunos servidores federais recebem uma bolsa-auxílio, redução de carga-horária em seu trabalho e aulas em um horário que facilita sua frequência, ou seja, entre $16 \mathrm{~h}$ e $19 \mathrm{~h}$, durante quatro dias por semana.

Várias histórias de vida eram contadas, desenhadas, entrelaçadas ao processo educativo da turma. Os alunos narravam diariamente os sucessivos fracassos e descaminhos que por fim os conduziram a estarem reunidos naquele espaçotempo escolar mesmo que tardiamente em suas vidas. Dentre as histórias contadas, o abandono da escola para a entrada no mundo do trabalho, a orfandade, as drogas, bem como a exclusão efetuada pelo próprio meio escolar se faziam presentes. Entre as atividades sempre era possível ouvir a cada dificuldade encontrada ou percepção de algum erro: "sou burro mesmo", "cabeça de porco", "cabeça de leitão", "a professora está judiando de nós", etc. Assim, era possível observar que muitas vezes os alunos narravam-se como incapazes de aprender, ao mesmo tempo em que sua persistência em frequentar as aulas, apesar de todas as dificuldades atestava que pareciam acreditar que eram capazes de adquirir mais conhecimentos.

Os procedimentos eleitos para a produção do material de pesquisa podem ser pensados como uma tentativa de gerar relatos da "prática vivida" dos estudantes para fins da análise aqui empreendida. As atividades foram realizadas em aulas centradas na discussão acerca da relação entre tecnologia, ciência e matemática. No início do processo, a professora pediu permissão aos alunos para gravar em áudio suas falas, tendo primeiramente recebido algumas respostas negativas e até caretas. Após explicar como se daria o trabalho, a docente disse que os nomes dos envolvidos não seriam divulgados, bem como qualquer fala que por ventura eles considerassem imprópria para exposição. Podemos dizer que o gravador foi, num primeiro momento, instrumento inibidor. A turma que sempre mostrou-se falante e participativa tornou-se por alguns minutos monossilábica e mesmo, silenciosa.

Passado o estranhamento inicial, os alunos passaram a expor suas ideias, ignorando a presença do objeto até então emudecedor. Pensando nas aulas realizadas na produção do material de pesquisa aqui escrutinado como se fossem uma entrevista, somos levadas a olhar aquele momento como um evento discursivo complexo, composto não apenas pela dupla entrevistador/entrevistado(s), mas por uma gama de imagens, representações e expectativas que ali circulavam - de ambas as partes - não apenas durante a entrevista, mas após, no momento de escuta e análise (SILVEIRA, 2007).

Desse modo, podemos afirmar que havia, sem sombra de dúvidas, expectativas por parte da professora/pesquisadora e havia expectativas entre os educandos. A professora se questionava: será que não estou conduzindo "demais" as falas dos alunos? Será que as perguntas estão adequadas? Do mesmo modo que os estudantes podiam estar pensando em tantas outras coisas no momento em que a atividade ocorria, conduzindo suas respostas de acordo com aquilo que imaginavam que a docente queria escutar ou até mesmo, tentando "boicotar" o empreendimento que se dava no momento.

Nesse sentido, tanto aqueles que "boicotavam" quanto aqueles que se esforçavam para falar aquilo que mais julgavam pertinente, aquilo que poderia ser a resposta certa ou mesmo o que agradaria a professora, estavam colocando em 
curso o que em uma clave foucaultiana chamaríamos de confissão. Compreender as falas dos sujeitos como confissões é pensá-las como discursos que produziriam mais efeitos não naqueles aos quais são dirigidos, mas naqueles mesmos que falam (FILHO, 2008). Ou seja, a confissão seria um "[...] conjunto imbricado de saberes e práticas relativos à subjetividade, colocados numa relação de incitação recíproca, onde o ato de verbalização, o exercício do discurso em relação a si mesmo, gera um conhecimento sobre o sujeito" (Id., p. 145).

Buscando "incitar as confissões" da turma de EJA, a professora primeiramente escreveu no quadro-verde quatro palavras: tecnologia, ciência, matemática e inovação. Após a leitura das palavras por parte daqueles que já estão alfabetizados, vieram as primeiras impressões dos sujeitos da pesquisa para romper o silêncio inicial: "Ih! Lá vem ela...", "Ciência é muito bom!?, "Que eu quero com isso daí?". Passado o primeiro "estranhamento" do grupo, passou-se a discutir quais relações eram possíveis de se estabelecer entre aquelas palavras e suas vidas.

Encerrada a primeira discussão, assistiu-se ao vídeo A tecnologia no mundo - Ano 2100(2016). Este vídeo é uma compilação de imagens de diferentes películas do gênero ficção científica que mostram avanços tecnológicos notáveis: alguns já em curso, alguns bastante avançados em relação ao que vivenciamos hoje e outros avanços impressionantes que já não nos parecem tão distantes. Trens voadores passando entre os arranhacéus ou cruzando um deserto sem trilhos, exércitos de robôs, guerras com extraterrestres, cirurgias sem nenhum toque humano, avanços nanotecnológicos, entre outros, assombram - talvez menos que há tempos atrás - sob uma música orquestral ágil e forte.

Após assistir ao filme, a turma discutiu acerca do que foi visualizado. Para finalizar, solicitou-se aos alunos a escrita de frases com as palavras escritas inicialmente no quadro, sendo que a professora serviu de escriba para os alunos ainda não-alfabetizados. Disso resultou a gravação de mais ou menos três horas de discussão, além das frases produzidas pelos estudantes. Essa gravação foi então transcrita e os excertos separados conforme iam surgindo os enunciados. Para fins desse estudo, destacamos alguns enunciados para análise: "a ciência e a tecnologia fazem o nosso mundo melhor", "tecnologia causa desemprego", "matemática está em tudo" e "a tecnologia precisa da matemática para avançar".

\section{A estratégia analítica}

Este trabalho constituiu-se alinhado a uma perspectiva pós-metafísica e, em particular, aos estudos foucaultianos. Podemos afirmar que tal abordagem retira-nos a estabilidade do solo firme proporcionado pela escolha a priori de uma determinada metodologia de pesquisa. Como alertam Veiga-Neto e Lopes (2010, p. 7), "[...] não há um solo-base por onde caminhar, senão que, mais do que o caminho, éo próprio solo sobre o qual repousa esse caminho é que é feito durante o ato de caminhar". Assim, se há disposição de escutar Foucault, "[...] o método não é o caminho seguro como queriam Descartes e Ramus, até porque nada mais é seguro, previsível: nem os pontos de partida, nem o percurso, nem os pontos de chegada" (Id., p.6).

O que queremos demarcar, com isso, é a impossibilidade de tornarmo-nos mudas frente ao material de pesquisa, que não foi coletado e não falaria por si. O material, assim como o modo de olhar para ele, foi sendo composto, moldado, fabricado - aos poucos. Não apenas o olhar, mas também os instrumentos que nos fariam olhar precisaram ser produzidos para que o objeto de pesquisa se fizesse presente. Parafraseando Foucault (2012), diríamos que nós tateamos, fabricamos, como pudemos, instrumentos destinados a fazer aparecer objetos.

Nesse sentido, tendo a transcrição das atividades que resultaram da produção do material investigativo, procuramos selecionar o que era recorrente, isto é, buscamos ver os enunciados que se faziam presentes nas falas dos alunos. Nesse processo, tentamos levar em conta o alerta de Deleuze (2006, p. 27) quando escreve sobre Foucault: "[...] o enunciado não é imediatamente perceptível, sempre estando encoberto pelas frases ou pelas proposições. É preciso descobrir seu 'pedestal', poli-lo, e mesmo moldá-lo, inventá-1o". Tal exercício mobilizou-nos uma atitude inquisitiva, tendo em vista que "[...] é preciso aprender o exercício da dúvida permanente em relação às nossas crenças, às nomeações que vimos fazendo por vezes há longo tempo, de tal forma que já as transformamos em afirmações e objetos plenamente naturalizados" (FISCHER, 2012, p. 103). Desse modo, os excertos foram organizados em séries, nas quais buscamos identificar as rupturas, as continuidades e as descontinuidades conservadas entre si. Isso implicou, portanto, fazer algumas escolhas, 
visando a tornar o trabalho investigativo possível e dinâmico, no tempo delimitado à sua escrita.

Os enunciados não seriam palavras, frases ou proposições, mas formações que se fazem visíveis quando os sujeitos das frases, os objetos da proposição e os significados das palavras mudam de natureza. Isso ocorre quando esses elementos tomam o lugar do "diz-se", distribuindo-se, dispersando-se na espessura da linguagem (DELEUZE, 2006). No caso desta pesquisa, podemos exemplificar isso ao observar que aquilo que os alunos falaram e aqui elegemos para escrutinar faz parte não apenas de suas ideias, mas daquilo que está presente nos documentos oficiais, no currículo escolar, nas propagandas das escolas privadas, nos desenhos animados voltados ao público infantil, entre outros.

Isso possibilita, como argumenta Fischer (2012, p. 103), questionar "[...] como algumas práticas acabam por objetivar e nomear de determinada forma os sujeitos, os grupos, suas ações, gestos, vidas". No caso desse trabalho, pensando em como muitas vezes os alunos mesmo se posicionavam como não-aprendentes ao se autodenominarem "burros", "cabeça de porco", "cabeça de leitão", podemos refletir o quanto as ideias e práticas que circulam sobre ciência, tecnologia e matemática os faziam sentirem-se deslocados - por causa do domínio restrito que apresentavam - num mundo em que tanto destaque tais temas recebem todos os dias.

\section{Concepções sobre ciência - tecnologia - matemática}

Um dos ideais essenciais onde se assenta o programa moderno da racionalidade plena "[...] é a crença no progresso social como consequência inexorável do desenvolvimento da ciência" (PARDO, 2007, p. 48). Tal ideal carrega consigo a suposição de que o avanço do conhecimento científico é transferido a toda sociedade, fazendo com que se construa uma ordem social melhor e mais justa. De certo modo, junto a essa suposição, há um pensamento que nos leva a acreditar que toda inovação na ciência é em si boa (IBIDEM). Como evidenciou Bocasanta (2013), a partir do escrutínio de um conjunto de materiais de pesquisa formado por documentos governamentais, regulamentos de feiras de Iniciação Científica, livros, desenhos infantis, entre outros, tal pensamento é recorrente e faz parte daquilo que nomeou como dispositivo da tecnocientificidade. Seguindo a autora, estamos utilizando aqui o termo tecnocientificidade acompanhando o entendimento de tecnociência utilizado por Castelfranchi (2008) em sua tese de doutorado:

neste trabalho a tecnociência não será apenas a integração ou fusão entre ciência e tecnologia.'Tecnociência' não remeterá somente à ideia de que as distinções clássicas entre tecnologia, ciência 'aplicada' e ciência 'pura' ou de 'base' (como tinha sido funcional chamá-la, respectivamente, no século XIX e XX) são hoje embaçadas e mais úteis se interpretadas como estratégias políticas ou mesmo como fábulas de fundação. Tecnociência não significa, neste texto, somente o modelo linear (pesquisa $\rightarrow$ conhecimento $\rightarrow$ tecnologia $\rightarrow$ sociedade), não explica a complexidade das osmoses entre ciência e sociedade. A tecnociência será analisada como o entrelaçamento entre os dispositivos de produção de conhecimento científico, as técnicas e o capitalismo no interior da racionalidade de governo atual (Id., p. 8-9, grifo do autor).

Ainda, seguindo Bocasanta (2013), optou-se pelo sufixo -dade como uma indicação de estado de coisas, qualidade, modo de ser deste nosso tempo (FERREIRA, 2009). Isso indica nossa compreensão de que o dispositivo da tecnocientificidade é datado, provisório e suscetível a transformações. Entender a tecnocientificidade como um dispositivo é pensá-la como "uma rede heterogênea de elementos que lhe dá visibilidade e ocultamento, nas formas discursivas e não-discursivas" (VEIGA, 2002, p. 91). A tecnocientificidade seria uma estratégia inscrita em jogos de poder, ligada a configurações de saber que deles emergem e que também os condicionam (Ibid.); ou seja, a tecnocientificidade pensada como estratégia de poder.

Isso ocorre porque Foucault (2008, p. 244) entende $\mathrm{o}$ dispositivo como um conjunto heterogêneo que contempla "[...] discursos, instituições, organizações arquitetônicas, decisões regulamentares, leis, medidas administrativas, enunciados científicos, proposições filosóficas, morais e filantrópicas". Além disso, o filósofo compreende o dispositivo como sendo de natureza primordialmente estratégica; portanto, "[...] trata-se no caso de uma certa manipulação das relações de força, seja para desenvolvê-las em determinada direção, seja para bloqueá-las, para estabilizá-las, utilizá-las, etc...”. (Id., p. 246). Ao funcionar como um dispositivo, a tecnocientificidade teria "uma 
função estratégica dominante", seria uma “[...] formação que, em um determinado momento histórico, teve como função principal responder a uma urgência" (Id., p. 246).

Nesse caso, essa "urgência" atribuiria à penetração do conhecimento científico e tecnológico no tecido social - de forma especial, por meio da instituição escolar e universitária -, uma função salvacionista em relação à nação, que somente assim poderia ser posicionada em um patamar diferenciado no cenário internacional. Nesse sentido, ciência e tecnologia surgem como fonte de "prosperidade, segurança, qualidade de vida e participação social" (BRASIL, 2001, p. 51). $\mathrm{O}$ social mesmo parece ligado ao conhecimento tecnocientífico. Ciência e tecnologia são entendidas como algo que devem perpassar todas as esferas da sociedade.

Dessa forma, não apenas espaços formais de Educação, como a escola, devem cumprir uma função democratizante em relação ao acesso ao conhecimento tecnocientífico. Os meios de comunicação, museus e exposições também devem dar conta do tema. Ao mesmo tempo, a ênfase nos aspectos econômicos envolvidos na crescente necessidade de ampliar o acesso da sociedade ao que existe de mais atual em termos de $\mathrm{C} \& \mathrm{~T}$ visa à inovação e, consequentemente, à "desobstrução do progresso". Em sentido estrito, ciência e tecnologia trariam progresso coletivo através do progresso individual que seria obtido através do acesso às mesmas.

$\mathrm{Na}$ analítica aqui realizada, observamos que tais ideias se fazem presente nas falas e frases produzidas pelos alunos durante a geração do material de pesquisa:

Aluno: Primeiro, tu tinha que mandar uma carta ou montar cavalo e ir lá na outra cidade chamar o camarada. Agora não precisa. Tem telefone. Tu liga e diz "ô fulano, bah, como é que tu tá?"...

Professora: Isso é ótimo. Olha como funcionava antigamente..

Aluno: Foi o começo da minha vida. Pra ti dar um recado pra uma irmã ou pra um parente, pegava um cavalo e viajava igual a um maluco. Até chegar na casa, que tudo morava longe, tudo no lombo dum cavalo, não tinha carro, não tinha ônibus. Os carros que tinha, não sei se a senhora já viu em quadrinho, deve ter visto, a medeloá. Um troço todo de pau, só tinha o motor de ferro. Professora: Medeloá? Era um carro?

Aluno: Era uma caminhoneta, que só tinha o eixo de ferro. As rodas pra botar, as rodas de pau.

Professora: Um carro com roda de pau?

Aluno: Com roda de pau. E tinha um motor de ferro. Foram os primeiros que apareceram. $\mathrm{O}$ cara ia pra frente na manivela pra poder arrancar. Não tinha bateria. Tudo a manivela. $\mathrm{O}$ motor dava-lhe um coice que te atirava longe. $\mathrm{O}$ primeiro caminhão que nós tivemos, meu mano e eu, era disso daí, tudo na manivela. Coisa mais difícil do mundo. E como renovou. A inovação, que agora tem até controle remoto dentro de um caminhão, tem tudo. $\mathrm{O}$ painel mostra tudo o que tu vai fazer.

Além desse diálogo, destacamos ainda algumas das frases escritas pelos alunos: "A tecnologia é evolução da humanidade para um mundo melhor". "Tecnologia veio para melhorar nosso ponto de vista". "Ciência é crescer, a sabedoria de ser mais". "A panela de pressão é uma tecnologia que faz o feijão mais rápido do que cozinhar na rua. Antes levava três horas para cozinhar uma panela de feijão. Hoje dá pra cozinhar em 45 minutos". "Para fabricação de um carro precisa tecnologia". "Um médico precisa de ciência na medicina". "O nosso país precisa de inovação e renovação em tudo o que tem direito". "Precisa tecnologia na presidência". "Precisa de ciência na saúde". "Precisa de tecnologia na segurança, inovação e ciência na educação e a matemática é o principal de tudo: tecnologia, ciência e inovação".

Os excertos evidenciam que os sujeitos da pesquisa estão capturados por enunciados que conformam o que aqui chamamos de dispositivo da tecnocientificidade. Entre eles, "ciência e tecnologia é fonte de progresso para todos", como escreveu um dos alunos. Ou, então, como redigiu outro: "A tecnologia é evolução da humanidade para um mundo melhor". E, complementam, dizendo que a tecnologia facilitou a comunicação entre as pessoas e mesmo o uso do automóvel, ou ainda, do quanto a panela de pressão, enquanto evolução tecnológica, tornou mais simples e rápido o cozimento do feijão.

Ao que nos parece, as engrenagens do dispositivo da tecnocientificidade estão funcionando satisfatoriamente bem no que concerne ao engajamento de todos em suas tramas. Entre as diferentes e numerosas estratégias que conformam o dispositivo da tecnocientificidade, está a democratização do acesso à ciência e tecnologia, que acaba surgindo em alguns documentos oficiais, revestida do caráter de "direito". Documentos como o livro Cultura científica: um direito de todos, produzido pela UNESCO e que se intitula como um 
texto "que tem o significado de uma contribuição da UNESCO para um momento estratégico da educação brasileira" (WERTHEIN, 2003, p. 11), instituem o acesso à ciência e tecnologia como uma bandeira e um direito, por exemplo.

Isso conduz a conduta dos sujeitos, engajando-os, afinal, "precisam" fazer valer seus direitos. Coloca todos no jogo e, aos melhores jogadores, promete o progresso individual - e, por consequência, o desenvolvimento social e econômico do país. Desse modo, é possível identificar nas falas dos estudantes, o desejo de entrar nesse jogo, aprendendo mais sobre informática, como expressou um deles:

Por isso seria muito importante se as escolas ensinassem nós a computação. Aprender mais... embora a gente já tá velho, mas a gente nunca esquece um pensamento da pessoa, em melhorar a situação da pessoa, né? E melhorar a situação da pessoa, tu estudando. Tu vai pra sala de aula, tu vai estudar, tu vai fazer os graus que eles querem, tu vai subindo, porque tu tá interessado naquilo, tu botou na tua cabeça que tu vai aprender informática, o... tem que ser... não adianta, se a pessoa não se interessar não vai conseguir vencer. Daqui uns tempos é tudo informática, não adianta nada. O trabalho pra gente é informática.

$\mathrm{Ou}$ ainda, indignando-se frente ao descaso do governo com a educação e a precariedade do ensino, que estaria alheio às evoluções tecnológicas da contemporaneidade. Como argumentou um estudante: "Mas falam em evolução, evolução, ficam falando em evolução, mas se o governo não faz nada, não acontece nada. Os homens lá em cima é que tem que começar a evoluir. Primeiro lugar educação".

Como podemos observar, o dispositivo da tecnocientificidade opera também pela condução das condutas (FOUCAULT, 2010) dos sujeitos, que levados a pensar o acesso à ciência e tecnologia como uma necessidade e um direito, passam a enunciar que querem fazer parte dessas tramas, que precisam aprender mais sobre computação, que se ressentem por entenderem que o governo não coloca a educação - e por conseguinte uma melhor aparelhagem da escola para ensinar mais sobre tecnologia - em primeiro lugar. Expressam, ainda, que gostariam que pelo menos seus descendentes tivessem oportunidades melhores do que aquelas que lhes foram ofertadas: "Nós sempre queremos ensinar nossas crianças, nossa juventude a aprender bastante porque o dia de amanhã será mais, cada vez mais difícil. Quem não tem estudo já era. Quem puder pagar uma graduação... porque vai ficar mais difícil”.

Por experiência própria, a maioria já passou por situações em que a falta de conhecimento tecnocientífico posicionou a si ou a seus pares de forma desfavorável, como um dos estudantes narrou acerca de seu trabalho junto à viação férrea na década de 1960. Segundo ele, primeiramente existia o trem Minuano que empregava maquinistas, foguistas, guarda-freios (responsáveis por puxar as alavancas que paravam os trens nas estações), além dos funcionários que faziam a manutenção dos trilhos. Com a chegada de um trem mais moderno, o Húngaro, ele viu muitos colegas perderem postos de trabalho, afinal o trem era moderno e não carecia mais de foguistas ou guarda-freios, apenas do maquinista, que também teve diminuídas suas obrigações pela quantidade de funções automáticas que existiam no veículo. Restaram ainda por um tempo os trabalhadores que faziam os trilhos, que ao finalizarem a troca dos mesmos, também foram excluídos de suas funções. Nesse sentido, expressou: "tá certo, a tecnologia é legal, mas tirou o serviço de muita gente". E outro colega completou: "e tem muito mais ainda pra perder!".

$\mathrm{Na}$ mesma linha, outro aluno acrescentou ao falar da fabricação de carros: "[agora, a fabricação de carros é] por robô. Só tem uma meia dúzia de gente lá pros controles, só". Isto é, mesmo sendo entusiastas da ciência e da tecnologia, como promotoras de progresso, visando "um mundo melhor" - conforme evidenciamos no início dessa seção - os sujeitos da pesquisa entendem o quanto não fazer parte do seleto grupo que consegue se sobressair frente aos conhecimentos tecnocientíficos num cenário de rápidas (e por que não dizer grandiosas) mudanças pode ser doloroso.

E, nessa discussão, qual o lugar atribuído à matemática? De que forma os alunos compreendem a articulação entre a matemática e os campos da ciência e tecnologia? Essas eram inquietações que também direcionaram a realização desta pesquisa. Inicialmente, pode-se dizer que todos os estudantes destacaram a relevância da matemática para o desenvolvimento da ciência e para impulsionar os avanços tecnológicos. Pode-se dizer, até mesmo, que suas enunciações mostram um lugar especial atribuído à matemática. Ela não está presente apenas em sua relação com a ciência e a tecnologia, mas "em todos os lugares". Um dos alunos assim expressou: "Os números estão em todos os lugares. 
Não existe sem. Onde tu vai tem números, matemática. Tá em tudo, em qualquer lugar que tu vai, tem matemática". E, para eles, esses "lugares" envolvem tanto a escola como as experiências vividas fora dela: “Aprender matemática é importante porque se eu for no mercado fazer umas compras, se der cem reais, saber o total que ia sobrar".

Podemos dizer que os alunos estão capturados pela possibilidade do conhecimento matemático tudo descrever e explicar, o que Walkerdine (1995, p.225) denomina de "poder da racionalidade ocidental". Essas evidências foram também encontradas no estudo de Knijnik e Wanderer (2006) quando foram examinados regimes de verdade sobre a educação matemática de jovens e adultos do campo. O material analisado reunia narrativas sobre a educação matemática geradas por educadores do campo do sul do país. As enunciações examinadas evidenciaram que os educadores entrevistados, assim como os sujeitos que participaram dessa pesquisa, destacavam a presença do conhecimento matemático em todos os lugares, como nas práticas de medir, contar, localizar, etc., produzidas em suas atividades cotidianas, dizendo até que suas vidas "eram uma matemática".

Além de posicionarem o conhecimento matemático como presente em todas as atividades humanas, até mesmo na ciência e tecnologia, os alunos que participaram desse estudo atribuíam um valor específico à matemática, vinculando-a com inteligência e com a garantia de "saber mais". Segundo um dos estudantes, a matemática possibilita às pessoas "não passarem por bobos". Já outro afirmou: "Matemática é saber mais". Essas ideias convergem com a análise empreendida por Quartieri (2016, p.245) quando destaca que a importância atribuída à matemática é evidenciada já na época de Platão, que a concebia como um conhecimento importante pela capacidade de "acessar o potencial do ser humano".

Refletindo sobre o pensamento platônico, a autora destaca que algumas concepções sobre a matemática emergem de suas ideias, como: a relevância dos números como forma de controlar e administrar o mundo, a aritmética como um saber essencial para as artes profissionais e a matemática como chave da compreensão do mundo. Na filosofia platônica, a matemática era concebida como "uma verdade independente de qualquer verificação empírica e os objetos matemáticos serviam de modelo ao mundo. $\mathrm{O}$ matemático não criava os objetos a respeito dos quais falava, mas os descobria" (Id., p.245). Decorre disso a noção de que a matemática "é um instrumento selecionador de elites" (Id., p.246).

Examinando mais atentamente as falas dos estudantes, percebemos ainda que ao associar matemática com "saber mais" e com a garantia de "não ser bobo", eles não estão se referindo a qualquer matemática. Trata-se daquela ensinada e aprendida na escola. Um aluno assim expressou: "Tu sabendo matemática, tu faz uma conta. Como eu fazia na cuca, queimando o "porongo". Agora na caneta é mais fácil de acertar os quebradinhos, os inteirinhos... Melhorou bastante". Aqui ele compara a matemática oral, que "fazia na cuca", com a escolar, que é "na caneta", posicionando a última como melhor do que a primeira. Essa superioridade da matemática escolar (e acadêmica), marcadas pela escrita, em relação àquelas produzidas nas formas de vida não-escolares, usualmente orais, é apresentada nos estudos de Knijnik (2006), Wanderer (2014) e Knijnik et al (2013). Knijnik (2006), apoiando-se em Petitat, mostra que, na Europa Medieval, as práticas educativas eram caracterizadas pela transmissão oral. Porém, nesse período, passam a emergir algumas rupturas nas ações educativas que se fazem presentes até os dias atuais, como a expansão da escrita e o seu caráter de superioridade perante os processos marcados pela oralidade.

Do exposto até aqui podemos dizer que, para os sujeitos que participaram dessa pesquisa, as áreas da ciência e tecnologia perpassam todas as esferas da sociedade, estando vinculadas à noção de progresso e desenvolvimento. Os alunos dizem da importância da ciência e da tecnologia para a vida em sociedade, argumentando que seus avanços facilitaram, por exemplo, a comunicação entre as pessoas e o uso de determinados objetos, como o automóvel e a panela de pressão. Capturados por essas ideias, dizem até mesmo que o acesso à ciência e à tecnologia é uma necessidade e um direito. $\mathrm{E}$, nesse processo, a matemática não permanece distante. Ocupa, sem dúvida, um lugar de destaque, não só para o desenvolvimento da ciência e para impulsionar os avanços tecnológicos, mas como uma área vinculada à inteligência, capaz de "acessar o potencial do ser humano".

\section{Conclusão}

A ideia de que o conhecimento científico e matemático são importantes para o bem-estar da 
sociedade tornou-se bastante comum nos dias de hoje. Essa ideia remonta ao século XX, com o nascimento de uma narrativa que conecta superioridade econômica e desenvolvimento de competência matemática do cidadão. Nesse sentido, todos teriam aprendido bem a lição: pais, políticos, empresários, professores e até mesmo as crianças (VALERO, 2013, p. 7).

Quem iria questionar a necessidade de cientistas, engenheiros e matemáticos para produzir o grande progresso tecnológico que fez o mundo atingir este alto ponto de desenvolvimento. - e de decadência também? A ideia de que a matemática - assim como a ciência -, com todas as suas aplicações em tecnologia, é o motor para alcançar as promessas da Modernidade e de que, portanto, seu ensino e aprendizagem são fundamentais para a constituição dos sistemas escolares de massa é tão antiga - ou nova quanto o final do século 19.

Nessa direção, pensar em um currículo escolar passou a significar pensar em educação matemática e em ciências como parte da lista de conteúdos a serem ministrados. Como nos aponta Valero (2013), se durante boa parte do século XX a preocupação principal dos matemáticos com a educação era formar uma elite intelectual altamente competente, priorizando-se a qualidade e não a quantidade de pessoas capazes de proporcionar esse valorizado conhecimento a outras disciplinas das ciências puras e do crescente número de campos da engenharia científica e aplicada; a ideia de que a matemática é para todos é datada do final do século $\mathrm{XX}$.

Assentada na garupa de um pensamento que vislumbra na matemática a chave para garantir a competitividade nacional na economia global do conhecimento, tal ideia não seria, como alerta Valero (Id.), inocente declaração de bons desejos para o futuro. Trataria-se de uma articulação com uma determinada visão normativa, cuja função seria orientar políticas e, sobretudo, intervenções baseadas em pesquisas para ampliar o alcance de todos a um conhecimento altamente valorizado como a matemática. Como não podia deixar de ser, a EJA, por fazer parte da engrenagem escolar, também está imbricada nesse esforço para engajar a todos na busca pelo domínio de conhecimentos tecnocientíficos e matemáticos.

Esses apontamentos se fazem presentes nesse texto que, entre seus resultados principais, mostra que as falas dos sujeitos dessa pesquisa fazem parte de enunciados que colocam os conhecimentos tecnocientíficos e matemáticos em um pedestal, em objeto de desejo, algo que, de antemão, eles reconhecem como sendo acessível a poucos. Esse era o caso de um dos alunos que, ao responder por que achava importante aprender ciência, disse: "Num mundo de hoje se tu não souber ciência, tá ruim. [...] Falar com um superior, né? Ciência faz parte disso aí... uma pessoa mais graduada que a gente, deve ser da ciência. [...] E a gente quer chegar lá, né? Devagarzinho". Outro aventou: "Ciência pode tudo. Ciência é modo de formar tecnologia". Na mesma direção, um estudante completou: "Ciência quer dizer que o pessoal estuda vários anos para ter aquela ciência, aquelas experiências que eles fazem. [...] Pra fazer ciência tem que ter cabeça... Ai, muita cabeça". O mesmo aluno ainda argumentou acerca de sua ideia de abrangência da matemática: "Os números estão em todos os lugares. Não existe sem. Onde tu vai tem números, matemática. Tá tudo em qualquer lugar que tu vai tem matemática".

Ou seja, como podemos perceber, os sujeitos da pesquisa tem noção do valor dado a esses campos do conhecimento na contemporaneidade e se mostram desejosos de fazerem parte desse mundo em que quem sabe mais sobre ciência, tecnologia e matemática "tem cabeça", é "mais graduado", "pode falar com um superior". De um lado, isso os move a estarem presentes em sala de aula todos os dias. De outro, reafirma que eles ainda não são parte ativa desse jogo.

\section{Referências}

ARAUJO, S. C.Pescando letras: diálogos interdisciplinares entre a educação ambiental e a alfabetização de jovens e adultos no contexto da pesca artesanal. 2011. 153 f. Dissertação (Mestrado em Desenvolvimento Sustentável) - Universidade de Brasília, Brasília, 2011.

ARAUJO JUNIOR, A. C. Histórias de vida penduradas em cordel: uma experiência de troca de saberes no ensino de biologia para jovens e adultos. 2011. 132 f. Dissertação (Mestrado Profissional em Ensino de Ciências) - Universidade de Brasília, Brasília, 2011.

A TECNOLOGIA NO MUNDO - ANO 2100. 
Entretenimento, 4'28". Disponível em:

$<$ https://www.youtube.com/watch?v=CD1FHjgMc2 Y>. Acesso em julho de 2016.

BOCASANTA, D. M. Dispositivo da tecnocientificidade: a iniciação científica ao alcance de todos. 2013. $233 \mathrm{f}$. Tese (Doutorado em Educação) - Universidade do Vale do Rio dos Sinos, São Leopoldo, 2013.

BRASIL. Livro verde: ciência, tecnologia e inovação. Brasília: MCT, 2001.

CASTELFRANCHI, J. As serpentes e o bastão: tecnociência, neoliberalismo e inexorabilidade. 2008. 380 f. Tese (Doutorado em Filosofia) Universidade Estadual de Campinas, Campinas, 2008.

COSTA, S. J.; STRIEDER, D. O ensino de ciências e a Educação de Jovens e Adultos - caminhos para a formação da cultura científica. In: I SIMPOSIO NACIONAL DE EDUCACÃO, 1., 2008, Cascavel. Anais... Cascavel: Unoeste, 2008. p. 1-15.

DELEUZE, G. Foucault. São Paulo: Brasiliense, 2006.

DI PIERRO, M. C. Notas sobre a redefinição da identidade e das políticas públicas de educação de jovens e adultos no Brasil. Educação e Sociedade, São Paulo, v.26, n.92, p.1115-1139, 2005.

DI PIERRO, M. C.; HADDAD, S. Transformações nas políticas de educação de jovens e adultos no Brasil no início do terceiro milênio: uma análise das agendas nacional e internacional. Cedes, Campinas, v.35, n.96, p.197-217, 2015.

FERREIRA, A. B. Novo dicionário Aurélio da língua portuguesa. Curitiba: Positivo, 2009.

FILHO, K. P. Uma genealogia das práticas de confissão no Ocidente. In: RAGO, M.; VEIGANETO, A. (orgs.) Figuras de Foucault. Belo Horizonte: Autêntica, 2008.p. 139-146.

FISCHER, R. M. B. Trabalhar com Foucault: arqueologia de uma paixão. Belo Horizonte: Autêntica, 2012.

FONSECA, M. C. R. Educação Matemática de Jovens e Adultos: especificidades, desafios e contribuições. Belo Horizonte: Autêntica, 2002.

O ensino de Matemática e a Educação Básica de Jovens e Adultos. Presença Pedagógica, Belo Horizonte, v.5, n.27, p.28-37, 1999.

FOUCAULT, M. Ditos e escritos IV: estratégia, poder-saber. 3. ed. Rio de Janeiro: Forense Universitária, 2012.

Do governo dos vivos: curso no Collège de France, 1979-1980: excertos. Rio de Janeiro: Achiamé, 2010.

Graal, 2008.

. Microfísica do poder. Rio de Janeiro:

KNIJNIK, G. Educação matemática, culturas e conhecimento na luta pela terra. Santa Cruz do Sul: EDUNISC, 2006.

KNIJNIK, G.; WANDERER, F. “A vida deles é uma matemática": regimes de verdade sobre a educação matemática de adultos do campo. Revista Educação Unisinos, São Leopoldo, v. 4, n.7, p.5661, 2006.

KNIJNIK, G. et al. Etnomatemática em movimento. Belo Horizonte: Autêntica, 2013.

LIMA, E. A. Educação Científica e Física ambiental: uma análise das percepções dos alunos da EJA em campanhas ambientais no estado de Mato Grosso. 2011. 93 f. Dissertação (Mestrado em Física Ambiental) - Universidade Federal de Mato Grosso, Cuiabá, 2011.

MACENO, N. G. Concepções de estudantes sobre a Ciência em uma turma de Educação de Jovens e Adultos. Ciência em tela, Rio de Janeiro, v.6, n.1, p. 1-13, 2013.

OLIVEIRA, I.; DIAS, A.; MOTA NETO, J.

Pesquisas em educação de jovens e adultos no Brasil: a presença de Paulo Freire. In: $35^{\mathrm{a}}$ REUNIÃO ANUAL DA ASSOCIAÇÃO NACIONAL DE PÓS-GRADUAÇÃ O E PESQUISA EM EDUCAÇÃO, 1., 2012, Porto de Galinhas. Anais... Porto de Galinhas: ANPED, 2012. p. 1-17.

PARDO, R. H. Verdad e historicidad: el conocimiento científico y sus fracturas. In: DÍAZ, E. (Org.) La posciencia: el conocimiento científico 
en las postrimerías de la modernidad. Buenos Aires: Biblos, 2007. p. 37-62.

QUARTIERI, M. T. Modelagem matemática e o privilegiamento da matemática escolar. In: WANDERER, F.; KNIJNIK, G. (org.). Educação matemática e sociedade. São Paulo: Livraria da Física, 2016.p. 227-255.

SILVA, H. T. R.; MOURA, T. M. S. Educação de jovens e adultos - EJA: desafios e práticas pedagógicas. Revista Eletrônica Interdisciplinar, Barra do Garças, v.3, n.9, p.31-36, 2013.

SILVEIRA, R. M. H. A entrevista na pesquisa em educação - Uma arena de significados. In: COSTA, M. V. (org.) Caminhos Investigativos II: outros modos de pensar e fazer pesquisas em educação. Rio de Janeiro: Lamparina editora, 2007.p. 119-141.

SOARES, L. J. G.; SILVA, F. R.; SOARES, R. C. Educação de Jovens e Adultos e propostas curriculares: (re)conhecer especificidades dos sujeitos. In: $37^{\mathrm{a}}$ REUNIÃO ANUAL DA ASSOCIAÇÃO NACIONAL DE PÓSGRADUAÇÃO E PESQUISA EM EDUCAÇÃO, 1., 2015, Florianópolis. Anais... Florianópolis:

ANPED, 2015. p. 1-18.

OLIVEIRA, I.; DIAS, A.; MOTA NETO, J. Pesquisas em educação de jovens e adultos no Brasil: a presença de Paulo Freire. In: $35^{\mathrm{a}}$ REUNIÃO ANUAL DA ASSOCIAÇÃO NACIONAL DE PÓS-GRADUAÇÃO E PESQUISA EM EDUCAÇÃO, 1., 2012, Porto de
Galinhas. Anais... Porto de Galinhas: ANPED, 2012. p. 1-17.

THEES, A.; FANTINATO, M. C. Estudo de caso com professores de matemática da EJA e suas práticas letivas. Horizontes, Itatiba, v.31, n.1, p.5162, 2013.

VALERO, P. Mathematics for all and the promise of a bright future. In: 8 CONGRESS OF EUROPEAN RESEARCH IN MATHEMATICS EDUCATION, 1., 2013, Turkey. Turkey: Manavgat-Side, Antalya, 2013, p. 1-23.

VEIGA, C. G. A escolarização como projeto de civilização. Revista Brasileira de Educação, Campinas, v. 21, p. 90-103, 2002.

VEIGA-NETO, A.; LOPES, M. C. Há teoria e método em Michel Foucault?: implicações educacionais. In: CLARETO, S.; FERRARI, A. (Org.). Foucault, Deleuze \& Educação. Juiz de Fora: UFJF, 2010. p. 33-47.

WALKERDINE, V. O raciocínioem tempos pósmodernos.Educação e Realidade, Porto Alegre, v.20, n.2, p.207-226, 1995.

WANDERER, F. Educação Matemática, jogos de linguagem e regulação. São Paulo: Livraria da Física, 2014.

WEIRTHEIN, J. Apresentação. In: SASSON, A. et al. Cultura científica: um direito de todos. Brasília: UNESCO, 2003. p. 7-9.

\section{Sobre as autoras}

Daiane Martins Bocasanta é pedagoga, Mestre e Doutora em Educação (UNISINOS). Professora do Colégio de Aplicação da Universidade Federal do Rio Grande do Sul.

Fernanda Wanderer é licenciada em Matemática (UFRGS), Mestre e Doutora em Educação (UNISINOS). Professora permanente do Programa de Pós-Graduação em Educação da Universidade Federal do Rio Grande do Sul.

Gelsa Knijnik possui Licenciatura em Matemática (UFRGS), Mestrado em Matemática (UFRGS) e Doutorado em Educação (UFRGS). É professora titular do Programa de Pós-Graduação em Educação da Universidade do Vale do Rio dos Sinos. Lidera o Grupo Interinstitucional de Pesquisa em Educação Matemática e Sociedade (GIPEMS), que integra o Diretório de Grupos de Pesquisa do CNPq.

Recebido em julho de 2016.

Aprovado em outubro de 2016. 